\title{
Insulin-induced vasodilatation and endothelial function in obesity/insulin resistance. Effects of troglitazone
}

\author{
C.J.J. Tack ${ }^{1}$, M. K.E. Ong ${ }^{1}$, J. A. Lutterman ${ }^{1}$, P. Smits ${ }^{2}$ \\ ${ }^{1}$ Department of Internal Medicine, Division of General Internal Medicine, University Hospital Nijmegen, The Netherlands \\ ${ }^{2}$ Department of Pharmacology, University Hospital Nijmegen, The Netherlands
}

Summary Insulin resistance is associated with a decreased vasodilator response to insulin. Because insulin's vasodilator effect is nitric oxide dependent, this impairment may reflect endothelial dysfunction. Troglitazone, an insulin-sensitiser, might thus improve insulin-dependent and/or endothelium-dependent vascular function in insulin resistant obese subjects. For 8 weeks, fifteen obese subjects were treated with either $400 \mathrm{mg}$ troglitazone once daily or placebo, in a randomised, double-blind, cross-over design. At the end of each treatment period, we measured forearm vasodilator responses (plethysmography) to intra-arterial administered acetylcholine and sodium nitroprusside; insulin sensitivity and insulin-induced vascular and neurohumoral responses (clamp); vasoconstrictor responses to $N^{\mathrm{G}}$-monomethyl-L-arginine (LNMMA) during hyperinsulinaemia; and ambulatory 24-h blood pressure (ABPM). Baseline data (placebo) of obese subjects were compared with those obtained in lean control subjects. Obese subjects were insulin resistant compared with leans (whole-body glucose uptake: $26.8 \pm 3.0 \mathrm{vs} .53 .9 \pm 4.3 \mu \mathrm{mol} \cdot \mathrm{kg}^{-1} \cdot \mathrm{min}^{-1}, p<$ $0.001)$. Troglitazone improved whole-body glucose uptake (to $31.9 \pm 3.3 \mu \mathrm{mol} \cdot \mathrm{kg}^{-1} \cdot \mathrm{min}^{-1}, p=0.028$ ), and forearm glucose uptake (from 1.09 \pm 0.54 to $\left.2.31 \pm 0.69 \mu \mathrm{mol} \cdot \mathrm{dL}^{-1} \cdot \min ^{-1}, p=0.006\right)$. Insulin-induced vasodilatation was blunted in obese subjects (percent increase in forearm blood flow (FBF) in lean $66.5 \pm 23.0 \%$, vs. $10.1 \pm 11.3 \%$ in obese, $p=0.04$ ), but did not improve during troglitazone. Vascular responses to acetylcholine, sodium nitroprusside and L-NMMA did not differ between the obese and lean group, nor between both treatment periods in the obese individuals.

In conclusion, in insulin resistant obese subjects, endothelial vascular function is normal despite impaired vasodilator responses to insulin. Troglitazone improved insulin sensitivity but it had no effects on endothelium-dependent and -independent vascular responses. These data do not support an association between insulin resistance and endothelial function. [Diabetologia (1998) 41:569-576]

Keywords Insulin resistance, troglitazone, insulin sensitisers, vasodilatation, obesity, endothelial function.
Received: 19 September 1997 and in revised form: 22 December 1997

Corresponding author: Dr. C.J.J. Tack, National Institute for Neurological Disorders and Stroke (NINDS) of the National Institutes of Health, Clinical Neuroscience Branch, Building 10, Room 6N252, 9000 Rockville Pike MSC 1424, Bethesda, Maryland 20892, USA. After July 1: University Hospital Nijmegen. PO Box 91016500 HB Nijmegen Tel: 31-24-3614782 Fax: 31-24-3541734 e-mail: c.tackdaig.azn.nz

Abbreviations: FBF, forearm blood flow; NIDDM, non-insulin-dependent diabetes mellitus; L-NMMA, N ${ }^{\mathrm{G}}$-monomethylL-arginine; $\mathrm{ACH}$, acetylcholine; SNP, sodium nitroprusside; NEFA, non-esterified fatty acids; TG, triglycerides; HDL, high density lipoprotein; ANOVA, analysis of variance; FVR, forearm vascular resistance; NE, norepinephrine; MAP, mean arterial pressure; ABPH, ambulatory 24-h blood pressure.
Besides its key role in the regulation of carbohydrate metabolism [1], it has become clear that insulin has important cardiovascular effects. Several authors, including ourselves, have shown that systemic hyperinsulinaemia induces vasodilatation in skeletal muscle [2-4]. This vasodilatation further enhances the delivery of glucose to insulin sensitive tissues, thus supporting insulin-induced glucose uptake [5]. Insulinmediated vasodilatation is diminished in insulin resistant states, like obesity [6], hypertension [3] and noninsulin-dependent diabetes mellitus (NIDDM) [7]. Because the vasodilator effect of insulin appears to be mediated by endothelial release of nitric oxide $[8$, 9], a diminished insulin-induced vasodilatation may 
reflect endothelial dysfunction. Indeed, in NIDDM $[10,11]$ and hypertension [12], an impaired endothelial function has been reported. These findings appear to imply that insulin resistance may be linked to endothelial dysfunction as either a cause or as a consequence [5]. Recent reports indeed claim a reduced vasodilator response to metacholine and not to sodium nitroprusside in insulin resistant obese individuals indicating a specific defect in endothelial-dependent vasodilatation [13].

Troglitazone is a recently developed compound, capable of improving insulin sensitivity [14-17]. If insulin resistance were coupled to endothelial function, improvement of insulin sensitivity would then possibly also improve endothelial function and hence vasodilator responses to insulin in insulin resistant states. To test this hypothesis, we performed a randomised, placebo-controlled, double-blind crossover trial with troglitazone in obese individuals characterised by insulin resistance.

\section{Subjects and methods}

Subjects. The study group consisted of 15 obese, healthy volunteers. All met the inclusion criteria: age between 25 and 50 years, non-smoking, absence of hypertension (office blood pressure $<140 / 90 \mathrm{mmHg}$, measured after $5 \mathrm{~min}$ rest in the supine position with mercury sphygmomanometer), body mass index between 27 and $36 \mathrm{~kg} \cdot \mathrm{m}^{-2}$. Participants used no medication; two women used oral contraceptives. Further history, physical examination and laboratory results showed no evidence of disease. All subjects had normal fasting glucose concentrations, normal $\mathrm{HbA}_{1 \mathrm{c}}$ concentrations and a stable weight. Baseline data obtained during the use of placebo (which was known after the completion of the trial) were compared with those obtained in a group of 13 age- and sex-matched lean individuals. Study participants were selected by advertisement and received a payment. All gave written informed consent. The experimental protocol was approved by the hospital ethics committee.

Vascular responses to acetylcholine/nitroprusside and $\mathrm{N}^{\mathrm{G}}$ monomethyl-L-arginine (L-NMMA) were assessed in 13 obese subjects. Two underwent only euglycaemic clamps. One of the obese subjects underwent minor surgery during the second part of the trial which was followed by complications and a subsequent weight loss of $6.4 \mathrm{~kg}$. This subject was excluded from the troglitazone portion of the study. Later it turned out that this individual had used placebo during the first part. Therefore, these data were included for comparison with the lean group.

Protocol. After inclusion in the study, obese subjects received either 2 tablets of $200 \mathrm{mg}$ of troglitazone once a day with or after breakfast or placebo for 8 weeks in a randomised, doubleblind, crossover design. The subjects, pharmacists and investigators were not aware of the treatment code which was broken only after completion of all analyses. Participants were strictly advised to maintain their weight. At the end of the two treatment periods 24-h ambulatory blood pressure monitoring (Profilomat, Disetronic Medical Systems, Burgdorf, Switserland, measurements every $15 \mathrm{~min}$ during day, every $30 \mathrm{~min}$ during night) was performed, followed 2 days later by an in-
Drugs and dosages $\left(\mu \mathrm{g} \cdot \mathrm{dl}^{-1} \cdot \mathrm{min}^{-1}\right)$ :

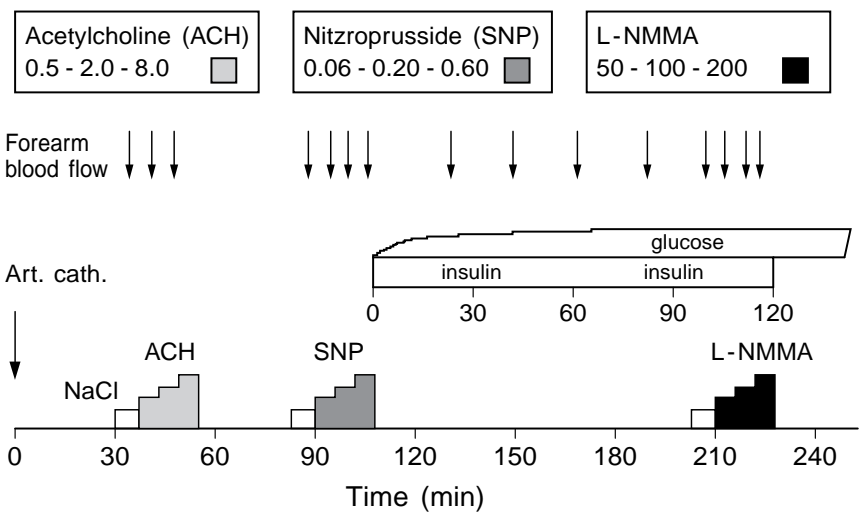

Fig. 1. Schedule of the study protocol

tra-arterial test with administration of vaso-active drugs into the brachial artery in combination with the euglycaemic hyperinsulinaemic clamp technique (see below). In addition, body weight, waist-hip measurements, ECG, fat skinfold thickness, possible side-effects, and serum safety chemical and haematological profiles were determined. Between both treatment periods there was a two week wash-out period. Compliance was monitored by pill counts and diary records. Lean control subjects underwent the investigational protocol once, a few days after baseline investigations.

Experimental procedures. Intra-arterial experiments were performed after an overnight fast, with the subjects in supine position in a quiet, temperature-controlled room $\left(23^{\circ}-24^{\circ} \mathrm{C}\right)$. A 20-gauge catheter (Angiocath, Becton Dickinson, Sandy, Utah, USA) was inserted into the left brachial artery (local anaesthesia with $0.3-0.4 \mathrm{ml}$ lidocaine $\mathrm{HCl} 20 \mathrm{mg} \cdot \mathrm{ml}^{-1}$ ), and connected with an arterial pressure monitoring line to a Hewlett Packard 78353B Monitor. In the ipsilateral arm a catheter (Venflon, BOC Ohmeda AB, Helsingborg, Sweden. 20 G, $32 \mathrm{~mm}$ ) was inserted retrogradely into a deep forearm vein to obtain venous blood samples. On the contralateral side an identical catheter was inserted into a large forearm vein for infusion of insulin and glucose $20 \%$.

Forearm blood flow (FBF) was measured in both arms simultaneously using mercury-in-silastic strain gauge, venous occlusion plethysmography as previously described [18]. One minute before the start of the measurements, a wrist cuff was inflated to $100 \mathrm{mmHg}$ above systolic blood pressure. The collecting cuff around the upper arm was inflated to a pressure of $40 \mathrm{mmHg}$ during 8 heart cycles using a Hokanson E20 rapid cuff inflator. The strain gauges were connected with the Hokanson EC4 plethysmographs (D. E. Hokanson Inc, Bellevue, Wash., USA). Forearm volume was measured with the water displacement method, and all drugs were dosed per $100 \mathrm{ml}$ forearm tissue (infusion rate $100 \mu \mathrm{l} \cdot \mathrm{dl}^{-1} \cdot \mathrm{min}^{-1}$ ). For the calculation of net uptake or release of glucose and potassium, arterial and venous blood was sampled simultaneously at relevant time points (see calculations). Venous blood was sampled with inflated wrist cuffs.

Measurements. A schedule of the protocol is shown in Figure 1. After complete instrumentation, 30 min of rest were included, after which baseline measurements were performed. Subsequently, three doses of acetylcholine $(0.5,2.0$ and $8.0 \mu \mathrm{g} \cdot \mathrm{dl}^{-1} \cdot \mathrm{min}^{-1}, 100 \mathrm{mg} /$ ampoule, dry powder [Dispersa AG, Winterthur, Germany] dissolved to its final concentration 
with normal saline), an endothelium-dependent vasodilator, were infused into the brachial artery. Each dose lasted 5 min, FBF was measured during the last 2 min of each 5 min period. Following, $30 \mathrm{~min}$ of equilibration were included. Subsequently, sodium nitroprusside (Roche, Mijdrecht, The Netherlands), an endothelium-independent vasodilator, was infused intra-arterially in three doses $\left(0.06,0.20\right.$ and $0.60 \mu \mathrm{g} \cdot \mathrm{dl}^{-1} \cdot \mathrm{min}^{-1}$, $50 \mathrm{mg} /$ ampoule, dry powder, dissolved with glucose $5 \%$ solution), each for $5 \mathrm{~min}$ with measurements for the last $2 \mathrm{~min}$.

Next, the euglycaemic hyperinsulinaemic clamp was started: Insulin (Actrapid, Novo-Nordisk, Copenhagen, Denmark) was infused intravenously in a dose of $430 \mathrm{pmol} \cdot \mathrm{m}^{-2} \cdot \mathrm{min}^{-1}$ $\left(60 \mathrm{mU} \cdot \mathrm{m}^{-2} \cdot \mathrm{min}^{-1}\right)$, for $120 \mathrm{~min}$. Insulin $50 \mathrm{U} \times \mathrm{ml}^{-1}$ was diluted in $47.5 \mathrm{ml} 0.9 \% \mathrm{NaCl}$ with the addition of $2 \mathrm{ml}$ human albumin $20 \%$ (Central Laboratory of Bloodtransfusion, Amsterdam, The Netherlands) to a concentration of $1 \mathrm{U} \cdot \mathrm{ml}^{-1}$. Euglycaemia was maintained by a variable infusion of glucose $20 \%$ solution, adjusted by arterial glucose measurements at $7 \mathrm{~min}$ intervals. Arterial blood glucose concentrations of all participants were clamped at fasting level minus $0.2-0.5$. When subjects underwent the second clamp procedure, the glucose clamp level was chosen identical to that of the first clamp.

Finally, to evaluate the contribution of endothelial NO release to the prevailing blood flow during hyperinsulinaemia $[8,9]$, three intra-arterial doses of the specific NO synthase inhibitor $N^{\mathrm{G}}$-monomethyl-L-arginine (L-NMMA [Sigma-Aldrich Chemie BV, Zwyndrecht, The Netherlands], 0.05, 0.1 and $0.2 \mathrm{mg} \cdot \mathrm{dl}^{-1} \cdot \mathrm{min}^{-1}$, dry powder, diluted with normal saline) were administered for $5 \mathrm{~min}$ each, with measurements for the last $2 \mathrm{~min}$. During L-NMMA, insulin (and glucose) infusion were continued. After the experiment, the glucose infusion was continued for a while and the participants were served a carbohydrate-rich meal in order to avoid post-test hypoglycaemic events.

Analytical methods. Plasma glucose was measured by the glucose oxidation method (Beckman Glucose Analyzer 2, Beckman Instruments Inc, Fullerton, Calif., USA). Plasma insulin was measured with a double antibody radioimmunoassay (Inter-assay coefficient of variation (CV) $6.2 \%$ ). Non-esterified fatty acids (NEFA) were analysed with an enzymatic method (ACS-ACOD, NEFA C-kit, Waco Chemicals GmbH Neuss, Germany). Triglycerides (TG,Triglycerides GPO-PAP method), cholesterol (Cholesterin CHOD - PAP method) and HDL-cholesterol (after addition of cholesterin precipitation reagens) were all determined on a Hitachi 747 auto-analyser (Boehringer Mannheim, Germany). Blood samples for measurement of plasma norepinephrine were collected in prechilled tubes on melting ice, containing glutathione $(0.2 \mathrm{~mol} / \mathrm{l})$ and EGTA $(0.25 \mathrm{~mol} / \mathrm{l})$, and centrifuged at $4{ }^{\circ} \mathrm{C}$. Norepinephrine concentration was determined by high performance liquid chromatography (HPLC) with fluorometric detection [19].

Calculations and data analysis. Assuming that whole blood glucose $=(1-0.3 \times$ haematocrit $) \times$ plasma blood glucose [20], glucose uptake was calculated as:

Glucose $_{\text {Arterial-Venous }} \times(1-0.3 \times$ haematocrit $) \times \mathrm{FBF}_{\text {Experimental arm }}$

Coefficients of plasma glucose variation during the last $30 \mathrm{~min}$ of the clamp were $3.1 \pm 04 \%$ in obese and $4.4 \pm 0.7 \%$ in lean subjects. Whole-body glucose uptake was defined as the glucose infusion rate during the last $30 \mathrm{~min}$ of the clamp and expressed in $\mu \mathrm{mol} \cdot \mathrm{kg}^{-1} \cdot \mathrm{min}^{-1}$ [21].

Statistical analyses were only performed after prior verification of appropriateness by exclusion of period or sequence effects [22]. Comparison of whole-body and forearm glucose uptake, metabolic data, blood pressure measurements and effects of insulin on FBF was performed with paired $t$ tests. Comparison between the two groups was performed using unpaired $t$ tests.

Before each set of drug infusions, baseline FBF measurements were obtained. The effects of vaso-active drugs on blood flow in the experimental arm were evaluated by comparing the dose-blood flow response curves. Although baseline FBF was not significantly different between both groups, FBF tended to be higher in the obese group. To compensate for these possible differences in baseline flow, responses to drugs were also expressed as percentage increase above baseline [23]. Differences were statistically tested with the use of repeated measures analysis of variance (ANOVA).

To avoid interference with the previously administered vasodilator drugs in the experimental arm (see Fig.1, schedule of the protocol), changes in FBF in the control arm were used for statistical evaluation of the effect of insulin on blood flow. The final two FBF measurements in the control side during sodium nitroprusside (SNP) (just before the start of insulin) were compared with the final two FBF measurements in the control side during L-NMMA (after 115 min insulin administration).

Effects of insulin on blood pressure and heart rate were evaluated using repeated measures ANOVA, with insulin as independent factor and data on the relevant time points as dependent variables. 24-h ambulatory blood pressure measurements were averaged to hourly values. Only data in which two sets were available from each subject were used for further analyses. One mean value was then calculated for the whole $24 \mathrm{~h}$ period (between $09.00 \mathrm{~h}$ and $07.00 \mathrm{~h}$ the next morning). Correlations were evaluated with Spearman's rank correlation coefficients. All statistical analyses were performed using the SPSS personal computer software package SPSS Inc, Gorinchem, The Netherlands. Results in tables and figures are expressed as mean \pm SEM, unless otherwise indicated. Significance was set at a $p$ value of less than 0.05 . NS indicates not significant.

\section{Results}

Characteristics of the two groups are shown in Table 1 . They were properly matched for age and sex. There was a clear difference with respect to weight, fat percentage and waist/hip ratio. Although all individuals were normotensive, mean office diastolic blood pressure was higher in the obese group. Mean plasma triglycerides (TG) and NEFA levels were higher, and HDL-cholesterol levels lower in the obese group.

Vascular responses to vaso-active drugs. Acetylcholine induced a dose-dependent increase in FBF in the experimental arm. The absolute or relative vascular responses were not different between lean and obese, nor were they affected by troglitazone (Fig. 2, upper panel). FBF in the control arm did not change. After 30 min FBF was back to baseline values.

Infusion of sodium nitroprusside induced a dosedependent increase in FBF in the experimental arm. Troglitazone did not affect the absolute or relative vascular responses to nitroprusside (Fig. 2, lower panel). FBF in the control arm did not change. Similar results were obtained when data were expressed in 


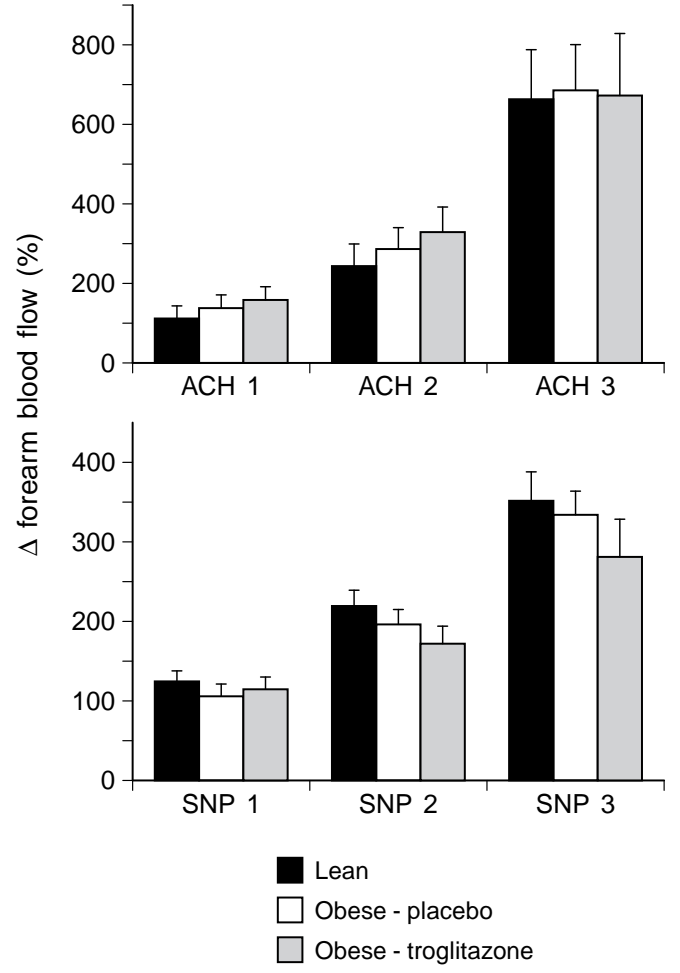

Fig. 2. Percentage increase in FBF in response to three subsequent doses of acetylcholine (top panel) and sodium nitroprusside (lower panel)

Table 1. Baseline characteristics (mean \pm SD)

\begin{tabular}{|c|c|c|c|}
\hline & Obese & Lean & $P$ \\
\hline Number $(\mathrm{M}: \mathrm{F})$ & $15(9: 6)$ & $13(7: 6)$ & \\
\hline Age (yr) & $37.4 \pm 4.6$ & $38.3 \pm 7.6$ & NS \\
\hline Weight $(\mathrm{kg})$ & $96.0 \pm 9.0$ & $69.1 \pm 10.5$ & $<0.001$ \\
\hline $\operatorname{BMI}\left(\mathrm{kg} \cdot \mathrm{m}^{-2}\right)$ & $31.7 \pm 2.9$ & $21.9 \pm 0.6$ & $<0.001$ \\
\hline Waist/Hip & $1.01 \pm 0.09$ & $0.86 \pm 0.06$ & $<0.001$ \\
\hline Fat $(\%)$ & $35.8 \pm 6.8$ & $22.6 \pm 6.2$ & $<0.001$ \\
\hline Cholesterol $\left(\mathrm{mmol} \cdot \mathrm{l}^{-1}\right)$ & $5.12 \pm 1.05$ & $4.84 \pm 1.06$ & NS \\
\hline HDL-Chol $\left(\mathrm{mmol} \cdot \mathrm{l}^{-1}\right)^{\prime}$ & $1.02 \pm 0.26$ & $1.28 \pm 0.26$ & 0.012 \\
\hline Triglycerides $\left(\mathrm{mmol} \cdot \mathrm{l}^{-1}\right)$ & $2.11 \pm 2.29$ & $0.80 \pm 0.40$ & 0.013 \\
\hline $\mathrm{NEFA}\left(\mathrm{mmol} \pm \mathrm{l}^{-1}\right)$ & $0.61 \pm 0.28$ & $0.38 \pm 0.22$ & 0.018 \\
\hline SYSBP (mm Hg) & $123 \pm 11$ & $118 \pm 10$ & NS \\
\hline DIAS BP $(\mathrm{mm} \mathrm{Hg})$ & $82 \pm 5$ & $73 \pm 11$ & 0.008 \\
\hline Heart Rate (bpm) & $69 \pm 7$ & $70 \pm 13$ & NS \\
\hline $\begin{array}{l}\text { Forearm blood flow } \\
\left(\mathrm{ml} \cdot \mathrm{dl}^{-1} \cdot \mathrm{min}^{-1}\right)\end{array}$ & $2.74 \pm 0.19$ & $2.25 \pm 0.75$ & NS \\
\hline
\end{tabular}

forearm vascular resistance $(\mathrm{FVR})$ or in ratio $\mathrm{FBF}_{\mathrm{ex}-}$ perimental arm $/ \mathrm{FBF}_{\text {control arm }}$.

Effect of troglitazone on metabolic parameters. Troglitazone was well tolerated, drug compliance was more than $95 \%$. Eight subjects used troglitazone first, while seven used placebo. There were no sequence or period effects during the trial; mean weight change, fasting plasma glucose/insulin, lipid levels, insulin sensitivity and blood pressure were comparable during the first and second period of the trial.

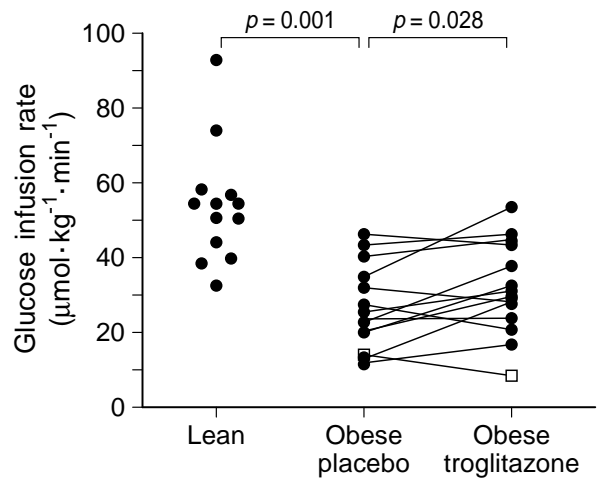

Fig. 3. Distribution of insulin sensitivity in both lean and obese subjects, and individual response of the obese subjects to troglitazone. The individual indicated with $\square$ had syncopal symptoms during the clamp (troglitazone treatment)

Fasting plasma glucose did not change during troglitazone treatment, fasting insulin concentration tended to decrease (placebo: 85.6 \pm 8.2 , troglitazone: $\left.69.8 \pm 6.8 \mathrm{pmol} \cdot \mathrm{l}^{-1}, p=0.11\right)$, but remained elevated compared with fasting levels in lean subjects $\left(40.9 \pm 5.0 \mathrm{pmol} \cdot \mathrm{l}^{-1}, p<0.001\right.$ vs. obese [placebo]). Body weight did not significantly change during both treatment periods (placebo: $+0.75 \pm 0.46 \mathrm{~kg}$, troglitazone: $+0.41 \pm 0.48 \mathrm{~kg}, p=\mathrm{NS})$. Troglitazone treatment was associated with slight decrements in $\mathrm{NEFA}$ (from $0.61 \pm 0.07$ to $0.47 \pm 0.05 \mathrm{mmol} \cdot \mathrm{l}^{-1}$, $p=0.06)$, total cholesterol, HDL-cholesterol and TG concentrations did not significantly change.

Metabolic response to euglycaemic hyperinsulinaemic clamping. Blood glucose values during the clamp procedure were similar in all experimental groups. In one obese subject near syncope occurred during one of the two clamps (troglitazone), but her data were included in further analyses.

Steady state plasma insulin concentrations during the clamp were in lean subjects $587 \pm 22 \mathrm{pmol} \cdot \mathrm{l}^{-1}$, in obese subjects $692 \pm 17 \mathrm{pmol} \cdot \mathrm{l}^{-1}$ (placebo, $p<0.01$ vs. lean), and $694 \pm 24 \mathrm{pmol} \cdot \mathrm{l}^{-1}$ (troglitazone, $p=$ NS vs. placebo). Obese subjects were clearly insulin resistant as compared with lean subjects; mean whole-body glucose uptake was $26.8 \pm 3.0$ (range 11.9-46.1), compared to 53.9 \pm 4.3 (range 32.7-92.2) $\mu \mathrm{mol} \cdot \mathrm{kg}^{-1} \cdot \mathrm{min}^{-1}$ in lean subjects $(p<0.001)$. During troglitazone, insulin sensitivity improved (wholebody glucose uptake to $31.9 \pm 3.3 \mu \mathrm{mol} \cdot \mathrm{kg}^{-1} \cdot \mathrm{min}^{-1}$, $p=0.028)$. Mean percentage increase in whole-body glucose uptake was $23.1 \pm 10.5 \%(p=0.047)$. Individual responses are shown in Figure 3.

Forearm glucose uptake under fasting conditions was $0.88 \pm 0.20$ in obese compared to $0.48 \pm$ $0.10 \mu \mathrm{mol} \cdot \mathrm{dl}^{-1} \cdot \mathrm{min}^{-1}$ in lean subjects, $p=\mathrm{NS}$. Insulin induced an obvious increase in forearm glucose uptake in both groups, but the increase was larger in the lean group: $1.03 \pm 0.45$ in obese subjects com- 
Table 2. Effect of troglitazone on blood pressure and heart rate

\begin{tabular}{lccl}
\hline & Placebo & Troglitazone & $p$-value \\
\hline $\begin{array}{l}\text { Systolic BP } \\
\text { intra-arterial }\end{array}$ & $129.2 \pm 3.1$ & $128.3 \pm 3.2$ & NS \\
ABPM - 24 h & $114.7 \pm 1.9$ & $113.9 \pm 2.9$ & NS \\
$\begin{array}{l}\text { Diastolic BP } \\
\text { intra-arterial }\end{array}$ & $71.2 \pm 1.6$ & $71.0 \pm 1.8$ & NS \\
ABPM - 24 h & $84.5 \pm 1.2$ & $81.5 \pm 1.6$ & 0.041 \\
Heart Rate & & & \\
intra-arterial & $59.8 \pm 3.1$ & $64.1 \pm 2.2$ & 0.021 \\
ABPM - 24 h & $71.8 \pm 2.1$ & $73.9 \pm 1.6$ & NS \\
\hline
\end{tabular}

Table 3. Cardiovascular responses to insulin

\begin{tabular}{|c|c|c|c|}
\hline & Baseline & Insulin & $p=$ \\
\hline $\begin{array}{l}\text { Systolic BP }(\mathrm{mm} \mathrm{Hg}) \\
\text { lean } \\
\text { obese }\end{array}$ & $\begin{array}{l}121.6 \pm 1.4 \\
131.9 \pm 2.8\end{array}$ & $\begin{array}{l}127.0 \pm 2.2 \\
138.0 \pm 3.3\end{array}$ & $\begin{array}{l}<0.001^{*} \\
<0.001^{*}\end{array}$ \\
\hline $\begin{array}{l}\text { Diastolic BP }(\mathrm{mm} \mathrm{Hg}) \\
\text { lean } \\
\text { obese }\end{array}$ & $\begin{array}{l}63.8 \pm 0.8 \\
72.8 \pm 1.5\end{array}$ & $\begin{array}{l}63.3 \pm 1.3 \\
73.1 \pm 1.2\end{array}$ & $\begin{array}{l}\text { NS* } \\
\text { NS* }\end{array}$ \\
\hline $\begin{array}{l}\text { Pulse pressure }(\mathrm{mm} \mathrm{Hg}) \\
\text { lean } \\
\text { obese }\end{array}$ & $\begin{array}{l}57.8 \pm 1.2 \\
59.2 \pm 1.8\end{array}$ & $\begin{array}{l}63.7 \pm 1.6 \\
64.9 \pm 2.4\end{array}$ & $\begin{array}{l}0.003^{*} \\
0.001^{*}\end{array}$ \\
\hline $\begin{array}{l}\text { Heart rate (bpm) } \\
\text { lean } \\
\text { obese }\end{array}$ & $\begin{array}{l}56.4 \pm 2.9 \\
59.2 \pm 1.8\end{array}$ & $\begin{array}{l}58.7 \pm 3.3 \\
64.9 \pm 2.4\end{array}$ & $\begin{array}{l}0.003^{*} \\
0.001^{*}\end{array}$ \\
\hline $\begin{array}{l}\text { NE }\left(\mathrm{nmol} \cdot \mathrm{l}^{-1}\right) \\
\text { lean } \\
\text { obese (placebo) } \\
\text { obese (troglita) }\end{array}$ & $\begin{array}{l}0.80 \pm 0.06 \\
0.92 \pm 0.08 \\
0.84 \pm 0.06\end{array}$ & $\begin{array}{l}1.06 \pm 0.10 \\
1.15 \pm 0.09 \\
1.14 \pm 0.08\end{array}$ & $\begin{array}{l}0.001 \\
0.006 \\
<0.001\end{array}$ \\
\hline
\end{tabular}

* by ANOVA, BP, blood pressure; NE, norepinephrine. Cardiovascular responses to insulin were not different between lean and obese subjects

pared to $3.23 \pm 0.47 \mu \mathrm{mol} \cdot \mathrm{dl}^{-1} \cdot \min ^{-1}$ in lean subjects $(p=0.003)$. Troglitazone increased insulin-induced forearm glucose uptake to $2.31 \pm 0.69 \mu \mathrm{mol}$. $\mathrm{dl}^{-1} \cdot \min ^{-1}(p=0.006$ vs. placebo $)$.

Haemodynamic parameters. Baseline FBF, systolic and diastolic (intra-arterially measured) blood pressure were not affected by troglitazone treatment. Heart rate increased significantly by $8.3 \pm 2.7 \%$ $(p=0.016)$, see Table 2. Mean ambulatory 24 -h diastolic blood pressure decreased during treatment with troglitazone, mean ambulatory 24 -h systolic blood pressure did not change (Table 2).

Cardiovascular effects of insulin. Insulin infusion increased systolic but not diastolic blood pressure in both groups. As a result, pulse pressure increased significantly (Table 3). Insulin infusion increased heart rate in both groups. Responses in blood pressure and heart rate to insulin were not different between the two groups and were not influenced by troglitazone.

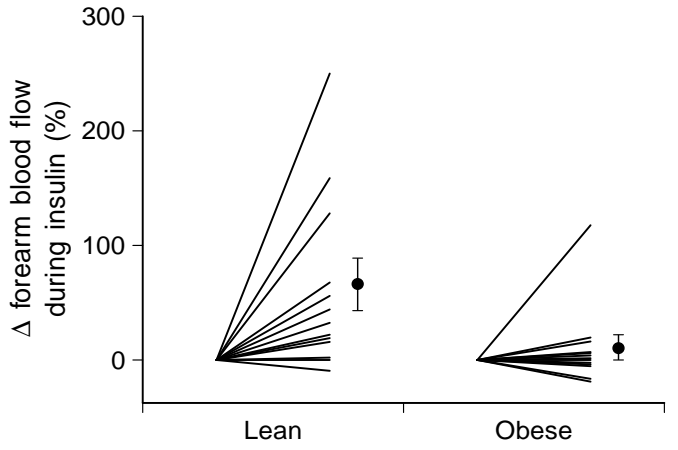

Fig. 4. Individual responses in percentage increase in FBF above baseline during insulin administration of lean (left) and obese subjects (right)

Baseline arterial plasma norepinephrine (NE) concentrations were similar in obese and lean subjects. Insulin infusion significantly increased arterial $\mathrm{NE}$ concentrations in both groups (percent increase in lean subjects $31.7 \pm 9.6 \%$, in obese subjects $33.4 \pm 7.6 \%, p=\mathrm{NS})$. Treatment with troglitazone did not change baseline arterial NE concentration nor the insulin-induced absolute or percentual increase in NE (all $p=$ NS vs. placebo) (Table 3 ).

Intravenous insulin infusion induced a gradual increase in FBF in the control arm (as well as in the experimental arm, but these changes were not used for analyses). Figure 4 shows individual vasodilator responses. Mean FBF in the control arm increased from $1.33 \pm 0.14$ to $2.15 \pm 0.32 \mathrm{ml}$. $\mathrm{dl}^{-1} \cdot \min ^{-1}(p=0.014$ vs baseline $)$ in the lean group, percentage increase $66.5 \pm 23.0 \%$. Insulin-induced vasodilatation was blunted in the obese group; FBF in the control arm from $1.87 \pm 0.22$ to $1.95 \pm$ $0.19 \mathrm{ml} \cdot \mathrm{dl}^{-1} \cdot \min ^{-1}(p=\mathrm{NS}$ vs. baseline), percentage increase in FBF $10.1 \pm 11.3 \%(p=0.04$ vs. lean group). The lack of effect of insulin on vascular tone in the obese subjects was not reversed by troglitazone (percentage increase in FBF during troglitazone $2.2 \pm 4.9 \%, p=\mathrm{NS}$ vs. placebo). Identical changes occurred when FVR instead of FBF was used for analyses.

Response to L-NMMA during hyperinsulinaemia. LNMMA infusion during systemic hyperinsulinaemia induced a dose-dependent vasoconstrictor response in the experimental arm in both groups. Due to the previous insulin effect in the lean group, FBF just before L-NMMA in the experimental arm was almost identical in both groups. Responses in the obese group were not different from those in lean subjects and were not affected by troglitazone. (Fig. 5). FBF in the control arm was not affected by L-NMMA infusion. During infusion of acetylcholine, nitroprusside and L-NMMA infusions, intra-arterial blood pressure remained stable throughout (data not shown). 


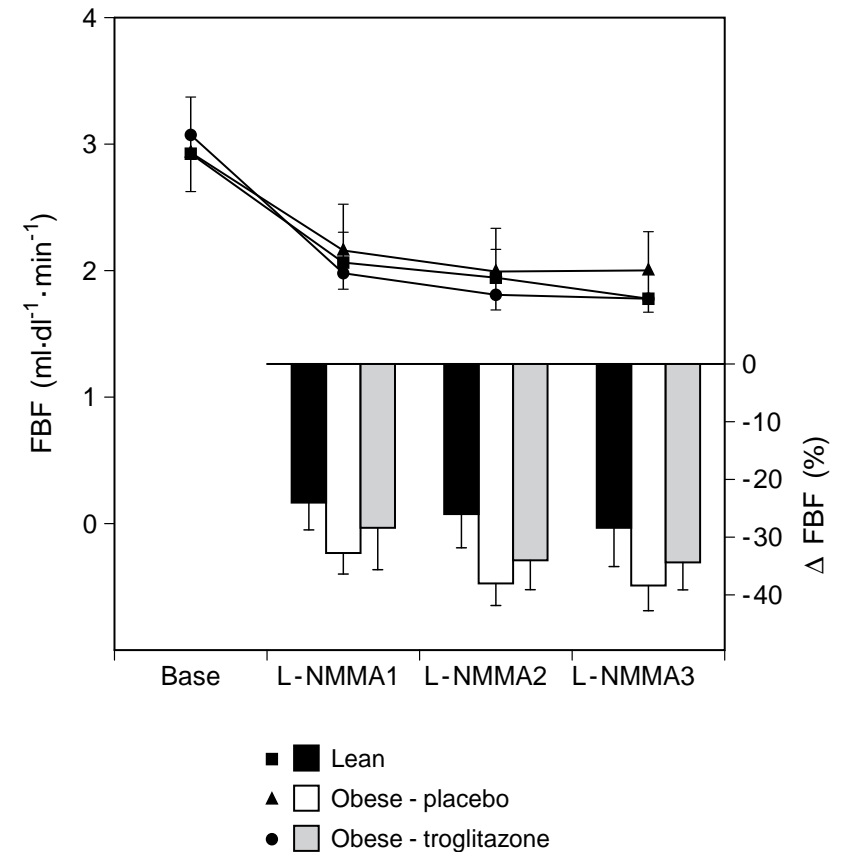

Fig.5. Absolute (top panel) and relative (in percentage, lower panel) changes in FBF during three subsequent doses of LNMMA, $p=\mathrm{NS}$

Correlations among metabolic parameters and vascular responses. In the combined group of lean and obese individuals, the correlation between the change in blood flow (\%) during insulin and insulininduced whole body glucose uptake was $r=0.39$ ( $p=0.056)$; between insulin-induced whole body glucose uptake and insulin-induced forearm glucose uptake $r=0.65(p<0.001)$, and between the change in blood flow (\%) during insulin and insulin-induced forearm glucose uptake $r=0.22(p=\mathrm{NS})$. No significant correlation was observed between vascular responses to acetylcholine and insulin sensitivity $(r=0.20, p=\mathrm{NS})$.

\section{Discussion}

The major observation of the present study is that obese subjects, despite the presence of a decreased insulin-induced glucose uptake (insulin resistance) and a decreased vasodilator response to insulin, show normal vascular responses to acetylcholine, sodium nitroprusside and L-NMMA. As such we found no evidence for endothelial dysfunction related to obesity/insulin resistance. This is confirmed by the observation that troglitazone did not affect vascular reactivity, whereas it significantly improved insulin sensitivity (whole-body as well as skeletal muscle glucose uptake increased).

Insulin-induced vasodilatation. Several investigators have reported that insulin induces vasodilatation in skeletal muscle [2-4], an effect that is impaired under conditions of insulin resistance $[3,6,7,24]$. In this study we confirm that insulin resistant obese subjects have blunted vasodilator responses to insulin [6]. In one study, insulin treatment in NIDDM patients in poor metabolic control improved insulin sensitivity as well as vasodilator responses to insulin [25]. This suggests that the vascular defect may be reversed by improvement of insulin resistance. In our study, however, we were not able to show any beneficial effect of troglitazone on insulin-induced increase in forearm blood flow despite a moderate improvement of insulin sensitivity. Given the relatively moderate effect of troglitazone, perhaps it may be unreasonable to expect a major increase in insulin-mediated vasodilatation, for, even during troglitazone treatment, insulin sensitivity was still considerably diminished in obese subjects compared with lean subjects. Therefore we cannot exclude that a pronounced increase in insulin sensitivity might result in greater insulinmediated vasodilatation. Currently however, there is no pharmacological therapy available that can achieve this target.

The lack of insulin-induced vasodilatation in our obese group cannot be based on structural changes in vascular function as suggested before [26], because responses to endothelium-dependent as well as independent vasodilators were absolutely similar with those in the lean group.

In this study we were not able to construct a full dose response curve of the effect of insulin on blood flow, although at the (high physiological) insulin concentrations obtained during the clamp, the discrimination between lean and obese subjects is expected to be most pronounced [6].

Endothelial function and insulin resistance. Two groups of investigators have reported that the vasodilator action of insulin can be blocked by the inhibitor of nitric oxide synthase L-NMMA, thus suggesting an endothelium-dependent mechanism of action $[8,9]$. Therefore, a diminished vasodilator response to insulin might reflect a disturbed function of the endothelium [5]. In keeping with this, a significant correlation between the response to L-NMMA (but not to acetylcholine) and insulin sensitivity was reported in normal subjects [27]. However, in this study we were not able to confirm this finding. We found no positive correlation between vascular responses to acetylcholine or L-NMMA (in contrast to the study of Petrie et al.) given during hyperinsulinaemia and insulin sensitivity, despite an even wider range in insulin sensitivity when lean and obese groups were combined. Also others found no such correlation in normal subjects [28] and in patients with essential hypertension [29].

Steinberg et al. described attenuated vasodilator responses to metacholine in insulin-resistant obese subjects [13]. Responses to the endothelium-depen- 
dent vasodilator acetylcholine and to the NO-inhibitor L-NMMA in our study, however, were absolutely similar between obese and lean subjects, despite large differences in insulin sensitivity between both groups. The number of subjects in our study was larger than in Steinberg's study. The study of Steinberg and ours show small, but probably relevant differences. Their study population (although strictly speaking normotensive), had higher blood pressure values (mean arterial pressure $(\mathrm{MAP}) \approx 100 \mathrm{mmHg}$ ) than ours (MAP $\approx 92.5 \mathrm{mmHg}$ ), possibly explaining part of the observed differences [12]. The vascular beds in which the investigations were performed were different. Steinberg et al. used metacholine instead of acetylcholine as endothelial-dependent vasodilator, which may not be purely nitric oxide dependent [30]. In contrast with the above mentioned studies, but in complete agreement with ours, are a number of recent reports indicating the absence of an association between insulin sensitivity and endothelial function in normal subjects [28], IDDM patients [31] and patients with essential hypertension [29]. Recently, in uncomplicated NIDDM, no correlation was observed between an index of in vivo NO generation and insulin sensitivity [32]. Furthermore, hypercholesterolaemia, a disorder that is firmly associated with disturbed endothelial function[33], is characterised by a normal insulin sensitivity [34]. Further studies will be required to gain more insight into this controversial area.

The absence of a specific defect in vascular endothelial function in obese, insulin-resistant subjects, despite a diminished insulin-induced vasodilatation, suggests that alternative mechanisms may be responsible for insulin-mediated vasodilatation. Recently, the role of ATP-dependent potassium channels [35] and $\mathrm{Na}^{+}-\mathrm{K}^{+}$-ATPase [36] has been reported as alternative mechanisms for insulin-induced vasodilatation, although these do not rule out possible involvement of the vascular endothelium.

Troglitazone and insulin resistance. In this study, obesity represents a situation of "pure" insulin resistance, with the advantage that changes in insulin sensitivity are not confounded by changes in blood glucose concentrations ("glucose toxicity") [37]. Obese subjects in our group exhibited well known features of the insulin resistance syndrome [38], with insulin sensitivity clearly different from lean subjects. Eight weeks of treatment with Troglitazone improved total-body as well as forearm insulin-mediated glucose uptake and tended to lower fasting insulin concentration. The increase in forearm glucose uptake appeared considerably higher than the increase in whole body glucose uptake, perhaps reflecting a specific beneficial drug effect on skeletal muscle glucose uptake. Furthermore, ambulatory diastolic blood pressure decreased slightly, and elevated NEFA lev- els showed a tendency to improve. These treatment results of troglitazone are consistent with earlier studies in humans [15-17]. However the changes under these strictly double-blind placebo-controlled conditions were modest and largely variable between individuals. A considerable difference from lean control subjects remained. In a recent study, evaluating the effects of troglitazone monotherapy on insulin resistance in NIDDM patients, a dose of $400 \mathrm{mg}$ troglitazone showed a maximum beneficial effect on glucose disposal [17]. This suggests that the dose in our study was high enough. Although our study duration may have been relatively short to exhibit a full effect, significant effects of the drug on metabolic parameters have been reported after 4-8 weeks [39]. The reported maximum increase in insulin-mediated glucose uptake was approximately $30 \%$ [16]. These data indicate that the true effect of troglitazone may be limited under the conditions of obesity/insulin resistance.

In conclusion, we report that insulin resistant, obese, normotensive individuals show a blunted vasodilator response to insulin despite preserved endothelium-dependent and -independent vascular responses. As such, these findings do not support an association between insulin resistance and endothelial function. Troglitazone improves metabolic parameters related to insulin sensitivity, but it does not change the effect of insulin on vascular tone nor on endothelial function.

Acknowledgements. This work was in part supported by a grant of the Glaxo Welcome Foundation.

\section{References}

1. Dinneen S, Gerich J, Rizza R (1992) Carbohydrate metabolism in non-insulin-dependent diabetes mellitus. N Engl J Med 327: 707-713

2. Anderson EA, Hoffmann RP, Balon TW, Sinkey CA, Mark AL (1991) Hyperinsulinemia produces both sympathetic neural activation and vasodilation in normal humans. $\mathbf{J}$ Clin Invest 87: 2246-2252

3. Baron AD, Brechtel-Hook G, Johnson AD, Hardin D (1993) Skeletal muscle blood flow. A possible link between insulin resistance and blood pressure. Hypertension 21: 129-135

4. Tack CJJ, Smits P, Willemsen JJ, Lenders JWM, Thien T, Lutterman JA (1996) Effects of insulin on vascular tone and sympathetic nervous system in NIDDM. Diabetes 45: $15-22$

5. Baron AD (1996) The coupling of glucose metabolism and perfusion in human skeletal muscle. Diabetes 45(S1): 105-109

6. Laakso M, Edelman SV, Brechtel G, Baron AD (1990) Decreased effect of insulin to stimulate skeletal blood flow in obese man. A novel mechanism for insulin resistance. J Clin Invest 85: 1844-1852

7. Laakso M, Edelman SV, Brechtel G, Baron AD (1992) Impaired insulin-mediated skeletal muscle blood flow in patients with NIDDM. Diabetes 41: 1076-1083 
8. Scherrer U, Randin D, Vollenweider P, Vollenweider L, Nicod P (1995) Nitric oxide release accounts for insulin's effects in humans. J Clin Invest 94: 2511-2515

9. Steinberg HM, Brechtel G, Johnson A, Fineberg N, Baron AD (1994) Insulin-mediated skeletal muscle vasodilation is nitric oxide dependent. A novel action of insulin to increase nitric-oxide release. J Clin Invest 94: 1172-1179

10. McVeigh GE, Brennan GM, Johnston GD et al. (1992) Impaired endothelium-dependent and independent vasodilation in patients with type 2 (non-insulin-dependent) diabetes mellitus. Diabetologia 35: 771-776

11. Cohen RA (1993) Dysfunction of vascular endothelium in diabetes mellitus. Circulation 87 (Suppl V):V67-V76

12. Panza JA, Quyyumi AA, Brush JE, Epstein SE (1990) Abnormal endothelium-dependent vascular relaxation in patients with essential hypertension. N Engl J Med 323: 22-27

13. Steinberg HO, Chaker H, Leaming R, Johnson A, Brechtel $\mathrm{G}$, Baron AD (1996) Obesity/insulin resistance is associated with endothelial dysfunction. J Clin Invest 97:2601-2610

14. Saltiel AR, Olefsky JM (1996) Thiazolidinediones in the treatment of insulin resistance and type II diabetes. Diabetes 45: 1661-1669

15. Suter SL, Nolan JJ, Wallace P, Gumbiner B, Olefsky JM (1992) Metabolic effects of new oral hypoglycemic agent CS-045 in NIDDM subjects. Diabetes Care 15: 193-203

16. Nolan JJ, Ludvik B, Beerdsen P, Joyce M, Olefsky J (1994) Improvement in glucose tolerance and insulin resistance in obese subjects treated with troglitazone. N Engl J Med 331: 1188-1193

17. Ghazzi MN, Perez JE, Antonucci TK et al. (1997) Cardiac and glycemic benefits of troglitazone treatment in NIDDM. Diabetes 46: 433-439

18. Brakkee AJM, Vendrik AJH (1966) Strain gauge plethysmography, theoretical and practical notes on a new design. J Appl Physiol 21: 701-704

19. Willemsen JJ, Ross HA, Jacobs MC et al. (1995) Highly sensitive and specific HPLC with fluorometric detection for determination of plasma epinephrine and norepinephrine applied to kinetic studies in humans. Clin Chem 41: $1455-1460$

20. Dillon RS (1965) Importance of hematocrit in interpretation of blood sugar. Diabetes 14: 672-674

21. Bergman RN, Finegood DT, Ader M (1985) Assessment of insulin sensitivity in vivo. Endocr Rev 6: 245-285

22. Hills M, Armitage P (1979) The two-period crossover clinical trial. Br J Pharmacol 8: 7-20

23. Benjamin N, Calver A, Collier J, Robinson B, Vallance P, Webb D (1995) Measuring forearm blood flow and interpreting the responses to drugs and mediators. Hypertension 25: 918-923

24. Vollenweider P, Randin D, Tappy L, Jequier E, Nicod P, Scherrer U (1994) Impaired insulin-induced sympathetic neural activation and vasodilation in skeletal muscle in obese humans. J Clin Invest 93: 2365-2371
25. Baron AD, Laakso M, Brechtel G, Edelman SV (1991) Reduced capacity and affinity of skeletal muscle for insulinmediated glucose uptake in non-insulin-dependent diabetic subjects. Effects of insulin therapy. J Clin Invest 87: 1186-1194

26. Rocchini AP, Moorehead C, Katch V, Key J, Finta KM (1992) Forearm resistance vessel abnormalities and insulin resistance in obese adolescents. Hypertension 19:616-620

27. Petrie JR, Ueda S, Webb DJ, Elliot HL, Connell JMC (1996) Endothelial nitric oxide production and insulin sensitivity. Circulation 93: 1331-1333

28. Utriainen T, Mäkimattila S, Virkamäki A, Bergholm R, Yki-Järvinen H (1996) Dissociation between insulin sensitivity of glucose uptake and endothelial function in normal subjects. Diabetologia 39: 1477-1482

29. Natali A, Taddei S, Quiñones Galvan A, et al. (1997) Insulin sensitivity, vascular reactivity and clamp-induced vasodilation in essential hypertension. Circulation 96: 849-855

30. Rongen GA, Smits P, Thien T (1993) $N^{\mathrm{G}}$-monomethyl-LArg reduces the forearm vasodilator response to acetylcholine but not to methacholine in humans. J Cardiovasc Pharmacol 22: 884-888

31. Mäkimattila S, Virkamäki A, Groop PH et al. (1996) Chronic hyperglycemia impairs endothelial function and insulin sensitivity via different mechanisms in insulin-dependent diabetes mellitus. Circulation 94: 1276-1282

32. Avagaro A, Piarulli F, Valerio A et al. (1997) Forearm nitric oxide balance, vascular relaxation, and glucose metabolism in NIDDM patients. Diabetes 46: 1040-1046

33. Chowienczyk PJ, Watts GF, Cockcroft J, Ritter JM (1992) Impaired endothelium-dependent vasodilation of forearm resistance vessels in hypercholesterolaemia. Lancet 340: $1430-1432$

34. Karhapää P, Voutilainen E, Kovanen PT, Laakso M (1993) Insulin resistance in familial and nonfamilial hypercholesterolemia. Arteriosclerosis and Thrombosis 13: 367-370

35. McKay MK, Hester RL (1996) Role of nitric oxide, adenosine, and ATP-sensitive potassium channels in insulin-induced vasodilation. Hypertension 28: 202-208

36. Tack CJJ, Lutterman JA, Vervoort G, Thien T, Smits P (1996) Activation of the sodium-potassium pump contributes to insulin-induced vasodilation in humans. Hypertension 28: 426-432

37. Rosetti L, Giaccari A, DeFronzo RA (1990) Glucose toxicity. Diabetes Care 13: 610-630

38. Reaven GM (1993) Role of insulin resistance in human disease (syndrome X): an expanded definition. Annu Rev Med 44: 131-141

39. Mimura K, Umeda F, Hiramata S et al. (1994) Effects of a new oral hypoglycemic agent (CS-045) on metabolic abnormalities and insulin resistance in type 2 diabetes. Diabet Med 11: 685-691 